\title{
Problems of Corporate Governance and Control Under Unstable Capital Risk in Modern Russia at the Beginning of the Twenty-First Century
}

\author{
Vladimir B. Zotov ${ }^{1}$, Fail M. Ibiatov ${ }^{1, *}$, Sergey V. Kulikov², Olga V. Mamatelashvili ${ }^{3}$, \\ Nailia H. Bikmetova ${ }^{4}$, Liliya F. Sultanova ${ }^{5}$
}

${ }^{1}$ Department of State and Municipal Administration, State University of Management, Moscow, Russia

${ }^{2}$ Department of Journalism of the Philological Faculty, Peoples' Friendship University of Russia (RUDN-university), Moscow, Russia

${ }^{3}$ Department “Economic Security”, Ufa State Petroleum Technological University, Ufa, Russia

${ }^{4}$ Department of Management, Informatics and General Scientific Disciplines, Eastern Academy of Economics, Law and Humanities, Ufa, Russia

${ }^{5}$ Department of additional professional education,Bashkir Academy of Public Administration and management under Head of the Republic Bashkortostan, Ufa, Russia

*Corresponding author. Email: fim1801@mail.ru

\begin{abstract}
The aim of the study is a comprehensive study of theoretical and methodological issues and the actual practice of managing corporate industrial structures, as well as the development of ways to improve the performance of their functioning in conditions of high economic risk in Russia at the beginning of the twenty-first century. In Russia, the national model of corporate governance is at the stage of formation, the management mechanisms are idle, not finding enough use for themselves in the new environment.
\end{abstract}

Keywords: unstable markets, demand structure, scenario planning, corporate management

\section{INTRODUCTION}

In the situation of total changes that occur in the Russian economy under the influence of systemic transformations in the world economy in conjunction with the processes of globalization and the influence of artificial intelligence, Russian economists face the issues of improving the management system. At the present stage, the management system of large business groups is constantly being updated. Vertically integrated holding companies are developing, united by a single planning, financing, coordination and control mechanism. The issues of successful management of corporations acquire a high level of relevance in the conditions of industrial hubs, which provide daughter companies with a certain level of independence.

Achieving the goal of creating an effective business requires defining the principles of building a company and preliminary modeling of the main operational processes.

The dominant problem of our time is the accelerated increase in the discrepancy between the world of the rich and the reality of the poor, which is enhanced by the processes of globalization and transnationalization [1]. We believe that the provocative factor of this discrepancy is the mechanism of corporatization of processes, which actively interacts with the state in the sphere of economy. The significant influence of factors of uncertainty and economic risk, as well as the insufficient knowledge of a number of methodological aspects of the development of big business in Russia, make it necessary to search for new forms and methods of corporate management that are adequate to the changing conditions of the business environment.

Corporate structures have received various assessments in the writings of economic theorists. Thus, according to one group of scientists, the Corporation is the basis for the effective construction of the national economy. The Corporation also establishes priority agreements in the development of certain sectors of the economy. The second group of scientists believes that negative trends prevail in the work of "mega-associations", causing significant harm to the development of human civilization as a whole [2]. 
We consider the subject of economic activity, proceeding from several basic positions. Thus, neoclassical economists argue that an enterprise, being a subject of economic activity, is equal to an independent organization in organizational, legal and economic terms, since such an enterprise processes the resources at its disposal into finished products. The very type of a enterprise is determined by its function of production. At the same time, the production function itself reveals a correlation: the total of production is equal to the sum of the factors spent. Achieving profitability becomes a fundamental criterion for success in the market. At the same time, an important indicator is the combined use of production resources while reducing costs and increasing profits [3]. Traditionally, neoclassics compare two main models: 1) perfect competition; 2) free market. It should be noted that experts in this area consider the free market as a kind of infinite universe of certain economic entities that live and function independently of each other, while they have maximum information about the specifics of supply and demand in the market. Dominant, established by the rules of the market economy, are enterprises of various forms of ownership, as well as the legalized system of contractual relations. The system of contractual relations itself includes the norms of interaction between economic entities developed in the course of economic and legal practice, which is reflected in legal documents concluded between market participants [4].

Modern specialists in Economics analyzing managerial processes in economic structures, with a focus on institutional theory, using universal and particular to the General provisions of management; based on the theory of accomplices, the obligatory accountability of the owners of the companies before all interested internal and external parties; with the application of the provisions of the Agency theory, based on the mechanism of corporate relations and based on the current tools, given Agency costs.

It should be noted that current theories on corporate governance at the forefront of the economic system put the understanding of the system as a kind of integrative object, which combines socio-economic processes in a locus and a certain chronotope. In addition, they pay attention to systemic multiplying effects, understanding their deterministic role in the emergence, growth and development of modern corporations [5]

The concept itself of "corporation" is interpreted as "an association, a community of persons united by a community of professional or class interests, or the most common form of management of large-scale production" [6]. The scale of activity and the seizure of single-type product markets link the notion of corporation with monopoly. In dictionaries a corporation is defined as "one of the forms of monopoly associations" [7].

There is no doubt that the concept of "Corporation" is related to the concept of "integration". In the context of economic theory, integration acts as the Union of diverse, often heterogeneous, parts into one whole, in which we observe co-dependence in the system with some degree of independent autonomy, which contributes to the unification of enterprises into giant transnational corporations, not only at the level of regions, but also entire countries. We agree that integration can be considered on some imaginary plane, and therefore it can be both vertical and horizontal, including diagonal, conglomerate at various levels (from micro to macro).

When we analyze the trends in the development of the Russian style of corporate governance, we will try to model the plastic ways of probabilistic inclusion of Russian corporations in the standardized system of corporate governance. For this internal insight is necessary, first of all, for the leaders of the Corporation. The change in management style is based on the need to perform a huge amount of diverse, multifaceted work, which is based on the challenges of management and marketing, which is the success of the business itself. This work involves several basic steps:

- perfect compliance with the goals of the Corporation and methods of motivation of its owners;

- reorganization of the Corporation to a tier of selfgoverning structures in which the owners act as supervisors initially to perform Supervisory functions;

- selection of the structure adequate to the tasks of the enterprise, considering such elements as the search for resources, the establishment of production, sales organization, the use of innovations, etc.;

- definition of the set of uniform rules of the Corporation, which is formulated as the main postulate of the corporate philosophy, and which is fixed in the main regulatory document of the Corporation;

- transformation of the philosophy of encouraging the main working personnel, especially top managers, to improve production efficiency.

They discover the problem of shareholder self-interest when they move from the Communist principle of "fair pay" to the real pay of each employee. At the same time, managers calculate the true contribution of each employee to both daily profit and corporate profit generation. When the share of corporate profit increases, then with it the prestige of the shareholder becomes more significant in the management decisions of the distribution of the share of profit. At the same time, at a low rate, motivation goes into the sphere of obtaining more acceptable payment for the quality and efficiency of work. Based on this, the system of remuneration in corporations is based on three pillars:

- non-secretive and real remuneration for work carried out on the basis of a contract that is legally binding for both parties;

- receipt of interest on a part of shares as income for a certain financial year;

- accessory payments and special benefits in accordance with the internal regulations of the Corporation, fixed by the Charter of the Corporation or other legal documents. Such a system of reward payments for top managers guarantees them a high level of income, because it 
actively encourages them to work even more efficiently. At the same time, the share of capitalized profit that belongs to them, shows a tendency to grow, proportionately increasing the portfolio of social benefits and expanding the space of guarantees in the Corporation. This solution allows to remove the existing dissonance between the pay of top managers of corporations and the results of the activities of corporations as such.

\section{METHODOLOGY}

The corpus of organizational and economic instruments of corporate governance is the subject of our research. Monitoring of the performance of Russian corporations, available in the public domain, shows that the rates of dividend payments are growing, so there is an increase in market capitalization. Business expansion is a key condition for increasing the assets of this business, so corporations are actively going to attract external financing, search for external investors, promotion on the stock market. Such difficult tasks facing Russian corporations dictate changes in the usual management standards towards the global rules of corporate governance with increased transparency of corporate activities.

Unfortunately, we have to recognize the fact that this process of transformation and infusion into the world practice of corporate governance does not affect the activities of all Russian companies. In our opinion, this situation has developed under the influence of objective and subjective factors: 1) state regulation and economic policy in Russia are chaotic; 2) Russian state regulation and economic policy depend on the political needs of authorities at all levels. Today, the Russian market is experiencing the potential danger of an unfortunate corporate takeover of small companies. In this regard, most Russian companies are formally to the disclosure of information. For example, a Standard and Poor's study in 2005 showed that only 28 Russian companies gave more than $50 \%$ of the probabilistic volume of public disclosure of information [8].

The improvement of the market and the publicity of the Russian economy gradually ensured the growth of attention of Russian companies to the management specifics of corporations. The rise of capitalization of the growing market of the Russian Federation, the admission to external financing, the progressive movement to the creation of long-term partnership programs and relationships, business expansion are achievable only in the created efficient situation of the effective management system of the Corporation. Today, significant companies are exploring the financial market as a resource key to Finance their work. For example," Gazprom "within three years (2003-2006) so has disposed to itself internal and external investors that has entailed providing securities of \$11,3 billion Similarly has arrived AFK "Sistema", including its subsidiaries: $\$ 3$ billion, it is necessary to consider that the competent policy of the company promoted creation of favorable investment image therefore issue of securities of initial placement in the market in volume of $\$ 2,5$ billion slightly lags behind JSC "Russian Railways" which has placed shares of the company for $\$ 2,1$ billion. Today, these companies are the leaders of competent corporate governance. However, medium-sized companies are afraid to take risks, so the percentage of co-operative resources is relatively small, since it is approximately $5-10 \%$ of the underlying capital. At the same time, experts predict the entry of a large number of medium-sized companies into the financial market. Consequently, key Russian companies began to operate productively with the tools of Bank lending and equity financing for the expansion of activities.

\section{RESULTS}

The reality of the present day strongly demands that creative approaches, which have replaced the old methods, be used to regulate the work of the Corporation as a kind of Association of legal entities that carry out independent activities, coordinated in order to achieve a single powerful result. In this case, the very creation of a reliable and robust system of cooperation of subjects acts at the forefront of management administration [9].

As a result, the profitability of management depends on the quality of financial management, including the combined structures within the system itself, and in addition, managerial efficiency is due to the study of the possibilities of probabilistic ways of solving business problems in both strategies and tactics [10].

Thus, the management of a Corporation is a complex, hierarchically determined system of relations between its links, which functions as a control of production/reproduction, the settlement of forms and scope of various duties with the operational correction of the methods of daily activities for the implementation of their own interests of dominant shareholders. In this regard, the development of the concept of corporate governance becomes the fundamental basis of the Corporation [11].

The initial distribution of ownership resulted in the dominant banking participation in the industrial sector. The cornerstone of the audit on the banking side was a combination of equity and credit financing. Simultaneously with this process there was a formation of the next private corporations which was accompanied by abuzus from insiders with disorganization and deviation from norms of shareholders. The emergence of market relations in Russia provokes the emergence of financial and industrial groups, which indicates the priority of the so-called Japanese-German corporate governance system. At the same time, the recent collapse of 2015, which was associated with the fall of the ruble and the collapse of the oil market, led to a rise in the cohesion of ownership and control factors. 
At the same time, companies that were aimed only at trading and financial operations were the first to lose. At the same time, the devaluation of the ruble itself, as well as the rise in energy prices, led to the emergence of free money in the Russian economy. When in 1998 the Russian government adopted a new law on bankruptcy, according to this law, the redistribution of property got a new start. At the same time, total corporate control has become the absolute norm in corporations as a corresponding reaction of major investors in the conditions of high-risk ambiguity and volatility of objective and subjective factors of the Russian corporate governance system. This event-driven canvas reinforced the corporate merger drive, resulting in dominant integration business groups such as Alpha Group and Interros. In these groups, Bank financing prevails, the tools of intersecting beneficial ownership of shares, interweaving of directorates are used. Considering the ownership structure of large Russian companies, one can say that a large owner dominates in most of them. Among the minority shareholders are foreign portfolio investors represented by various investment funds and banking groups.

We consider it necessary to focus on the fact that large Russian companies distribute their assets quite specifically. It is known that the family model of management is one of the most established and has more than one century. The very institution of the family in the world presentation supports the concentration of property in one clan. The difference between management in Russia is that modern Russian companies are never built on this principle. Here the Soviet period had its profound influence on the nature of the formation of corporations. As a rule, a Russian Corporation begins with a team of like-minded people from three to seven people, who later become the main owners of the business, while they have acquired many informal ties among themselves. We can identify the nature of their interaction as a partnership, it is not by chance that they create partner firms. This form of distribution of property is the most common and preferred in Russian realities. According to experts, the share of primary owners varies on average from $35 \%$ to $40 \%$ in the total capital of industrial enterprises in Russia. Another trend of the Russian economy, which should be mentioned, is the increase in the Supervisory function of the state, which has become actively involved in business activities. The sphere of state control is growing, while state control is being introduced into the specifics of the corporate sector. In this regard, public-private partnerships are becoming a popular form of interaction between the state and private business. Thus, the most popular companies with state participation, such as Gazprom, Rosneft, Vneshtorgbank, which are active in various financial markets.

The uniqueness of the Russian corporate governance system is that it does not meet any of the globally recognized corporate models: neither the Anglo-Saxon, nor the Japanese - German, nor the Italian (family) management model. The events of Russian history contributed to the formation of a special system, so the Russian model is a multivariate, mobile, quickly responding to changes arising as a result of work within the Corporation, and as a response to external influences, so the criteria of the Russian model of subordination are quite shaky. For example, both the external and internal environment of the Corporation has a high level of uncertainty, which corresponds to the shortcomings of Russian legislation. At the same time, the giants of Russian corporate structures partially use different elements of all known models of corporate governance. This approach suggests that the further development of the Russian corporate governance system will develop its own way, without focusing on any specific model-scheme of business implementation [3].

Based on the above, we can say that the national business model of corporate governance is in the stage of formation in Russia, while the experience of other countries is taken into account, but does not prevail over their own research, so in Russian realities none of the recognized models of business management in the world practice prevails.

\section{DISCUSSION}

The primary stage of the formation of market relations in Russia is due to the formation of corporate entrepreneurship. The next stage was the process of formation of business structures with the subsequent formation of the business management system. It was a period of overcoming quite objectively difficult obstacles [12]. Of course, first of all, these are such banal reasons as: 1) the termination of interaction between enterprises, which were previously United in one economic complex; 2) the total shortage of market infrastructure; 3) technical primitiveness and technological retrograde of the majority of former giant enterprises; 4) low qualification and shortage of managerial personnel who can work effectively in market conditions; 5) lack of convincing scale of condensed capital; 6) vulnerability and insolvency of the financial system of the country as a whole [13, 14]. The 1990s were characterized by a total privatization process in Russia, which became the source of the emergence of many joint-stock companies. The announced reorganization of property was expressive, affecting all layers of Russian society, with an emphasis on the Anglo-Saxon model of business management [15]. The initiators of the reform proceeded from the following position: privatization of state property will lead to the need to create a mechanism of control and adjustment on the part of the stock market. However, the collapse of the state property system without any legal justification for further operation led to a spontaneous collapse of the property market and the emergence of many fraudulent schemes for the acquisition of parts of state property in one hand. By the end of the 90s, around 1997, there were more than one and a half thousand professional 
participants in the stock and securities market. At the same time, they received 16 licenses to conduct shareholder activities. The management of large state corporations was ready for such a turn of events, as at the end of 1997, 17 Russian companies appeared on the world market, issuing receipts of the American Depositary [16]. So, we consider the following components to be the key features of the evolution of the Russian national business management model:

- continuing the procedure of the recycling of ownership in corporations;

- the supervision of financial flows, coupled with the sequencing and evacuation of corporate assets, has led to the creation of a variety of specific motivations for most of the leading insiders, which are managers at different levels and the major shareholders themselves;

- the classic format of "external" structures of business management, which organically includes the securities and shares market itself, the institution of financial insolvency, the market of separate supervision;

- state ownership of the predominant share in the authorized capital, as well as problems in management and control in connection with such participation;

- the role of the Federal structure in the development of public-private partnership; the dominant influence of regional authorities as an Autonomous element of corporate relations, which also performs a regulatory function with the use of administrative resources to resolve issues;

- counterproductive and selective coercion by the state with a bias towards politicization of interpretations of actions in the presence of legally protected rights of shareholders [17].

Rating agencies show an increased interest in these problems, encouraging expert evaluation activities.

The growth of transnational corporations determines the importance of the problems of intercultural communication and intercultural interaction between employees, which requires training and other work to reduce the ethno-linguistic and cultural dichotomy " our " / "other"[18, 19]. This will increase the efficiency of the Corporation. Thus, we can argue that the General humanitarian circumstances of corporate life can negatively / positively affect the economic stability in society. It is no coincidence that multinational corporations regularly conduct trainings on team building.

\section{CONCLUSION}

The business management system is regulated by the following steps:

1) a set of complete register of conditions that have any negative impact on the company's performance, inhibiting its improvement;

2) regular analytical screening of motives provoking the occurrence of adverse external and internal factors;
3) expert monitoring of the consequences manifested under the influence of adverse conditions both in a single case and in combination;

4) expert assessment of the probabilistic appearance of critical, shadow situations: in a single manifestation and combined fusion;

5) hierarchization of detected risk factors by graded levels of possible threat for efficient production and further improvement of the company;

6) construction of the concept of permanent monitoring, implemented in the conditions of the company, which preventatively works, notifying about the possible negative balance of the audited indicators;

7) step-by-step carrying out set of procedures that reduce potential negative incidents and, in the case of the depreciation of the precedent they will improve the stability of the psychological microclimate in the company;

8) probable modeling of negative scenarios of development with the subsequent analysis; preparation and adjustment of system of anti-crisis measures which are mechanically included at achievement of the designated limit values in supervised signs.

However, the presence and implementation of preventive measures does not guarantee a positive outcome of the event. As a rule, experts consider the likely scenario with the worst outcome. Whatever actions are taken, it is necessary to proceed from the fact that the worst option of all probabilistic scenarios of the situation will come true, and as a result, the company will meet with a real collapse. However, when the company's management is interested in the stability of all team members from the bottom to the top. It creates a whole scaled set of measures to reduce the negative impact of the crisis event, it gives confidence that the decline will be minimized [20]. Practice convincingly proves that the problem of total scarcity of various kinds of resources is especially acute in a crisis. Simultaneously, at this time, the unproductiveness of the old, "pre-crisis" management patterns become noticeable and requires changes in management algorithms. We will try to present separate probabilistic solutions in case of crisis:1) personnel reserve.

2) consolidation of all possible sources (human, technical, financial, strategic, etc.);

3) crisis settlement and anti-crisis management;

4) operative staff.

Each solution contains detailed instructions that must be followed strictly. The use of the Institute of Deputy key managers in addressing anti-crisis measures can be of great help. The following is the regulation on the functionality of the head with a ranked list of responsibilities. An important point is to create a special plan to increase the importance of the employee and identify the traits that are exposed in a crisis situation [21]. Based on this, each Deputy head will perform the duties of the head for one week. In this case, the Manager acts as a supervisor. 
After going through such a stressful event, each Deputy will clearly distinguish between negative, potential negative, background noise and positive. Also, he is trained not to react to the flow of negativity in a crisis, while he has the opportunity to supervise his immediate superior or supervisor, standing higher in rank in the Corporation. This practice reveals both positive and negative features of each applicant, allowing him to climb the hierarchical ladder of personnel during the year with the minimization of economic and human damage. When the practice of "head of the day" covers the entire company, the result will be a well-built, dedicated to the mission of the company personnel, which is important for the progressive deployment of the business, and for force majeure. In addition, such experiments motivate managers of all tiers to work creatively with full dedication [22].

We consider it useful to compile a register of necessary actions. Such a pre-prescribed list of measures in a situation of force majeure makes it possible to understand what resources will be required depending on the crisis situation, since often explicit and effective solutions can be lost in the mass of information, since simple solutions have not attracted attention.

As you know, in Russia, the largest shareholder of all large companies is the state. The priority of the state as a shareholder is that the state as a shareholder controls the primary strategic enterprises and natural monopolies. Natural monopoly is an important argument in favor of the nationalization of industries important to society and the state. Such as, for example, the railway industry.

At the same time, analysts suggest that privatization is the main reason for the rather poor quality of business management in Russian companies. Of course, there are other circumstances that have paved the way for the offenses that took place in the last decade and received a wide public response.

- We have a poor performance of the corporate governance mission due to corruption in the judicial system. We regret to say that Russia is experiencing an acute shortage of highly qualified managers, since the financial market itself has just begun to develop, and in the harsh conditions of Western sanctions. This situation requires the involvement of risk managers. In addition, the rudimentary state of the financial market cannot exert even minimal pressure on companies, so the mechanism of guaranteed equipment according to the rules of business management increases the acquired importance for the establishment of a more perfect, effective system of corporate governance. At the same time, we observe distortions in the management apparatus. For example, justified claims and statements of shareholders to law enforcement agencies often remain unsatisfied and / or unclaimed. As a rule, judicial procedures take a very long time, the very qualification ranking of judges is very insignificant, and the judicial system itself in Russia suffers losses of reputation capital due to corruption.

- And like a sweet berry on top of the cake, the information that the Federal securities market
Commission (FSMC) not only does not have any financial resources, but also has no rights in the area of financial responsibility to recover from certain deviants real fines. To date, the maximum fine is about $\$ 5$ thousand, which is not a loss for public-private partnerships.

- The difficulty of organizing collective action. The country has a high concentration of ownership: the lion's share of the share capital belongs to insiders, and external shareholders do not have enough power to follow the business process. Investment funds, which, like banks, are ideal candidates for the role of active external investors and champions of effective corporate Difficulty in organizing coordinated collective actions. Russia is a country with a Gulliver-like sky-high concentration of property in comparison with the bulk of the Lilliputians. Insiders have most of the equity, simultaneously with these external shareholders do not have the convincing rights and power to control the nuances of the entire business process. Investment funds and banks can be the most optimal candidates not only as active external investors, but also as advocates of productive corporate governance. Unfortunately, these financial institutions do not have the proper motivation to carry out such a serious mission, and since this mission is not encouraged by the state, these structures do not seek to substitute themselves for such a difficult task. Today's Russia is experiencing time pressure due to the lack of convinced and dedicated advocates of the introduction of a highly developed and high-tech system of corporate governance. We include American institutional investors, various investment funds located both in Europe and in America, and in the Middle East, in the Asia-Pacific region. Knowledge of the ethnocultural characteristics of the country where the Fund is located can contribute to the conclusion of fruitful cooperation.

- Personnel vacuum as a designation of the shortage of experienced managers. Today, Russian top managers in companies represent the strongest class of owners, with the exception of natural monopolies and defense enterprises. Regional top managers have a special weight in their companies, which are implemented locally and are focused on the region. Links in the regional chain, where capital managers with a sufficient stake are firmly insured against any encroachments, as control over external investors is practically not carried out, are built up one after another. As a result, these owners-managers conduct transactions and all kinds of trading operations, primarily only for the sake of their own profits, without revealing a desire to introduce effective methods of corporate governance in companies.

- Patterns of old thinking. Each person is unique, but in some ways we are similar - this is true, because each type (old and new thinking) has positive sides and negative, so they complement each other. If we recall the planned economy of the Soviet period of development of our country, we will find that the management of enterprises was directly subordinated to state bodies. Based on this, we can understand why it is difficult for current managers 
to adapt to the real need to report to the Board of Directors. In addition, the activities of modern Directors are aimed at obtaining short-term personal profits, while the development of plans for medium-and long-term strategic development is not carried out due to the complexity of multi-stage, expensive restructuring. In this regard, the regional management continues to implement the outdated traditions of the once powerful centralized management of the Soviet era, which leaves a negative imprint on the company's activities.

So, corporate governance in Russia has already managed to face several problems, for the solution of which certain measures need to be applied.

\section{REFERENCES}

[1] L.P. Shmat'ko, Improving the efficiency of the use of regional intangible assets in local markets, Cand. Econ. Sciences. Dis., 2014.

[2] G. Latfullin, A. Raichenko, Organization Theory, Yurayt, 2016.

[3] I.N. Chuev, T.M. Panchenko, V.S. Novikov, O.A. Konnova, N.G. Iraeva, I.S. Karabulatova, Innovation and Integrated Structures of the Innovations in Modern Russia, International Review of management and marketing 6(1S) (2016) 239-244.

[4] S.A. Lyausheva, I.S. Karabulatova, Z.O. Abregova, Z.A. Mamisheva, L.V. Usova, Problems of Innovative Development in the Modern Ethno-cultural Environment, Astra Salvensis 6(12) (2018) 745-751.

[5] F. Analoui, A. Karami, Strategic management of small and medium-sized enterprises, Thomson, 2005.

[6] Kamal E. Nabeel, Al Mulla A. Mahmood, I.S Karabulatova, A.S. Karabulatova, The Arab East and Russia: Current transformations of multinational corporations, ISPR RAS, 2016.

[7] I. Bernard, J.C. Collie, Explanatory economic and financial dictionary, Inter. Rel, 1994.

[8] Standard and Poor's Corporate Rating Service, Information Transparency Survey of Russian Companies 2005, 2010, Available at: https:/gaap.ru/articles/sluzhba_reytingov_korporativno go_standard_poor_s_issledovanie_informatsionnoy_pr ozrachnosti_rossiysk/.

[9] L. Shkvarya, I. Karabulatova, V. Rusakovich, A. Rapiev, The impact of the customs union and the EAEU on the small and medium business in
Kazakhstan, Central Asia and the Caucasus 18(1) (2017) 93-100.

[10] S.G. Karepova, I.S. Karabulatova, V.S. Novikov, S.V. Klemovitsky, D.I. Stratan, A.E. Perova, New Approaches to the Development of Methodology of Strategic Community Planning, Mediterranean Journal of Social Science 6(3) (2015) 357-364.

[11] A. Anisimov, Phenomenon of a large corporation, or what market we need, Russian economic journal 8 (1992).

[12] M. Bobina, Strategic interfirm alliances, Questions of economy 4 (2002) 96-100.

[13] L.I. Abalkin, The logic of economic growth, Moscow, 2002.

[14] Yu.V. Vertakova, I.A. Kozieva, E.N. Kozbozhev, Management decisions: development and selection, textbook, KNORUS, 2010.

[15] G.R. Latfullin, O.N. Gromova, Organizational behavior, Moscow, 2006.

[16] B. Ixs, R. Ryterman, From enterprise to firm: notes on the theory of the enterprise in transition, Questions of Economics 8 (1994) 31-39.

[17] O.A. Koryakovtseva, I.I. Doronina, T.M. Panchenko. I.S. Karabulatova, Z.M. Abdullina, Research of category "Motivation" as a basic tool of personnel management, International Review of Management and Marketing 6(1S) (2016) 293-299.

[18] I.S. Karabulatova, S.A. Lyausheva, A.A. Nagoy, A.Y. Rozhkov, E.S. Studenikina, The problem of "Our/Others" in the discourse of intercultural communication and the new challenges of globalization and migration, Interciencia Journal 43(8) (2018) 177-192.

[19] V.V. Zelenskaya, S.A. Golubtsov, I.S.

Karabulatova, I.A. Kanon, Z.S. Kasyanova, Innovative Discourse in the Formation of a Modern EthnoCultural Environment, Astra Salvensis 6(12) (2018) 753-766.

[20] V.I. Goncharov, Management: Textbook, Allowance, Misanta, 2012.

[21] M.C.P. Rojas, P.H.G. Hernández, N.W.A. Niebles, Human resource administration as factor of business productivity for continuous improvement, Espacios 41(08) (2020) 10. 
[22] N.R. Saenko, A.A. Sozinova, I.S. Karabulatova, I.V. Akhmetov, O.V. Mamatelashvili, E.E.

Pismennaya, Research in Action Integrated Marketing Communications as the Elements of Information and Virtualization Market Relations, International Review of management and marketing 6(1S) (2016) 267-272. 